\title{
Hubungan Dukungan Suami dengan Keikutsertaan Ibu Akseptor KB IUD Di Puskesmas Mandiangin Kec. MKS Di Kota Bukittinggi Tahun 2019
}

\author{
Media Fitri ${ }^{1, *}$, Cindy Amalia Putri ${ }^{2}$ \\ ${ }^{1}$ STIKes Yarsi Sumatera Barat Bukittinggi, Jln. Tan Malaka Belakang Balok, Bukittinggi dan 26136, Indonesia \\ ${ }^{2}$ STIKes Yarsi Sumatera Barat Bukittinggi, Jln. Tan Malaka Belakang Balok, Bukittinggi dan 26136, Indonesia \\ ${ }^{1}$ Email : mediafitri09@gmail.com*; ${ }^{2}$ Email : cindyamaliaputri@gmail.com \\ * corresponding author
}

ARTICLE INFO

Keywords

Husband's support

IUD family planning acceptors

\section{ABSTRACT}

Family planning $(\mathrm{KB})$ is an action that helps husband and wife to avoid unwanted pregnancies, get a very desirable birth, adjust the pregnancy interval, and control the time of birth in relation to the age of the husband and wife and find the number of children in the family. Pregnancy control in the family planning program is carried out using contraceptives so that the husband's support is needed. The purpose of this study is to see the relationship between husband's support and the participation of IUD family planning acceptors at Puskesmas Mandiangin, MKS Bukittinggi District, 2019. This research was conducted in July 2019. Research methodology analytic survey with Cross Sectional design. The population was family planning acceptors by taking samples of 69 IUD family planning acceptors. Data processing and analysis were performed by computerization using the Chi Square statistical test at a significance limit of 0.05 . The results showed that $\rho=.0 .013$. From this value, it is known that the value of $\rho$ $<0.05$, which indicates that there is a relationship between husband's support and participation in IUD family planning. This relationship is also supported by the value of the OODs ratio $=0.769$, which means that a wife who can get support from the mother will have a chance of 0.769 times to become an IUD KB acceptor. It can be concluded that there is a relationship between husband's support and participation in KB IUD in the Work area of the Mandiangin Puskesmas, MKS District, Bukittinggi City, 2019 with a p-value $(0.013<0.05)$. It can be suggested that the husband should provide support to his wife in using contraception, both emotional support and in the form of appreciation support, in order to create a happy family.

\section{Pendahuluan}

Jumlah penduduk yang besar dan laju pertumbuhan penduduk yang tinggi merupakan masalah yang dihadapi bangsa Indonesia sekarang ini. Menurut World Population Data Sheet tahun 2013, Indonesia merupakan negara ke-5 di dunia dengan estimasi jumlah penduduk terbanyak, yaitu 249 juta. Di antara negara ASEAN, Indonesia salah satu negara dengan luas wilayah terbesar dengan penduduk terbanyak [1].

Laju pertumbuhan penduduk Indonesia dari tahun ke tahun semakin meningkat, dapat dilihat data jumlah penduduk Indonesia tahun 2014 sebanyak 252.20 juta jiwa, meningkat dibandingkan jumlah tahun 2013 sebanyak 248.80 juta jiwa [2]. Laju pertumbuhan penduduk ditentukan oleh tingkat kelahiran dan kematian, adanya perbaikan pelayanan kesehatan menyebabkan tingkat kematian penduduk rendah, sedangkan laju tingkat kelahiran tetap tinggi hal ini merupakan penyebab utama ledakan jumlah penduduk. Tingginya angka kelahiran merupakan alasan utama diperlukannya pelayanan Keluarga Berencana (KB) [2]. 
Keluarga Berencana (KB) adalah tindakan yang membantu pasangan suami istri untuk menghindari kehamilan yang tidak diinginkan, mendapatkan kelahiran yang memang sangat diinginkan, mengatur interval kehamilan, dan mengontrol waktu saat kelahiran dalam hubungan dengan umur suami istri serta menemukan jumlah anak dalam keluargan. Pengendalian kehamilan dalam program KB dilakukan dengan menggunakan alat kontrasepsi [2].

Kontrasepsi adalah usaha untuk mencegah terjadinya kehamilan. Metode kontrasepsi dapat dibagi berdasarkan jangka waktu pemakaian yaitu Metode Kontasepsi Jangka Panjang (MKJP) dan non MKJP. MKJP yang terdiri dari Intra Uterine Device (IUD), Metode Operasi Pria (MOP), Metode Operasi Wanita (MOW), dan implant, sedangkan non MKJP terdiri dari kondom, pil, dan injeksi [3].

Pengguna kontrasepsi di dunia menurut World Health Organization (WHO) lebih dari 100 juta wanita menggunakan kontrasepsi yang memiliki efektifitas, dengan pengguna kontrasepsi hormonal lebih dari $75 \%$ dan $25 \%$ menggunakan non hormonal. Dan pengguna kontrasepsi di dunia pada tahun 2005 mencapai 89\%. Tahun 2007 angka pengguna KB modern di perkotaan mencapai 58\% sedangkan di pedesaan mencapai 57\% [1].

Cakupan peserta KB di Indonesia pada tahun 2014 dengan jumlah sebanyak 47 juta Pasangan Usia Subur (PUS). Peserta akseptor KB baru yang menggunakan IUD sebanyak 7,15\%, sedangkan akseptor KB aktif yang menggunakan IUD sebanyak 11,07\%. Dari data diatas bahwa cakupan KB IUD masih tergolong rendah dibandingkan kontrasepsi suntik. Hal ini disebabkan oleh beberapa faktor yang sering terjadi di masyarakat, diantaranya adalah pengetahuan yang kurang, status ekonomi yang rendah, kurangnya dukungan suami serta pengaruh budaya yang tidak dianjurkan menggunakan kontrasepsi IUD. Namun dari beberapa faktor tersebut apabila tidak ada hal yang bisa mendorong ibu untuk menggunakan kontrasepsi IUD, tidak aka nada yang menggunakan IUD. Sehingga untuk meningkatkan pelayanan dan penggunaan kontrasepsi IUD, dukungan suami juga sangat diperlukan dalam pemilihan alat kontrasepsi. Cakupan KB IUD masih sangat kecil sehingga untuk meningkatkan pelayanan dan penggunaan KB IUD dapat dikaitkan dengan keunggulan meskipun efek samping dari KB IUD juga harus diketahui [3].

Dalam keluarga, suami mempunyai peranan sebagai kepala keluarga yang mempunyai peranan penting dan mempunyai hak untuk mendukung atau tidak mendukung apa yang dilakukan istri sehingga dukungan suami dalam penggunaan metode kontrasepsi IUD sangat diperlukan. Dengan adanya dukungan suami mengenai kontrasepsi yang dipakai oleh istri menyebabkan pemakaian IUD dapat berlangsung terus-menerus yang merupakan usaha untuk penurunan tingkat fertilitas. Seringkali tidak adanya keterlibatan suami mengakibatkan kurangnya informasi yang dimiliki seorang suami mengenai kesehatan reproduksi terutama alat kontrasepsi [4].

Dari penelitian Kurniati (2012) di Kecamatan Gunungpati, dari 10 orang didapatkan, 1 orang memilih alat kontrasepsi IUD. Dikarenakan adanya dukungan dari suami yang bisa mendukung ibu untuk memilih alat kontrasepsi. Serta mengurangi rasa menakutkan dan menganggap IUD memiliki keunggulan yang tinggi. Sedangkan 9 dari 10 orang tidak memilih IUD karena salah satu yang di takutkan masyarakat yaitu dimasukkan lewat jalan lahir, serta kurangnya mendapatkan dukungan dari suami karena suami belum mengetahui tentang kontrsepsi IUD sehingga pemilihan kontrasepsi IUD.

Penelitian lain dari Bernadus dkk (2013) didapatkan hasil bahwa dukungan suami mempunyai hubungan yang bermakna dengan keikutsertaan ibu memakai kontrasepsi IUD di Puskesmas Jailolo. Hasil penelitian berbeda dilakukan oleh Kusumaningrum dan Palarto (2009) dalam penelitiannya mengatakan bahwa tidak ada hubungan antara dukungan suami dengan pemakaian alat kontrasepsi IUD.

Badan Kependudukan dan Keluarga Berencana Nasional (BKKBN) Sumatera Barat menyatakan, peserta Keluarga Berencana (KB) di provinsi itu telah mencapai 60,74\%, dan berada diatas rata-rata nasional. Kepala perwakilan BKKBN sumbar menyatakan, pencapaian peserta KB sudah terdata hingga juli 2014 , dimana dari data tersebut jumlahnya telah mencapai $60,74 \%$ sedangkan rata-rata nasional adalah 58,33\% [3]. 
Survey Data dari Dinas Kesehatan Bukittinggi tahun 2018 didapatkan data pada 7 wilayah puskesmas, dimana pada puskesmas Guguk Panjang terhitung 586 peserta KB IUD aktif dan 24 peserta KB IUD pasca persalinan. Pada Puskesmas Rasimah Ahmad terhitung 266 peserta KB IUD aktif dan 12 peserta KB IUD pasca persalinan. Pada Puskesmas Mandiangin dengan jumlah peserta KB IUD aktif sebanyak 48 orang dan jumlah peserta KB pasca persalinan sebanyak 13 orang. Pada Puskesmas Nilam Sari terhitung 66 peserta KB IUD aktif dan 20 peserta KB IUD pasca persalinan. Pada Puskesmas Gulai Bancah terhitung 200 peserta KB IUD aktif dan 34 peserta KB IUD pasca persalinan. Pada Puskesmas Plus Mandiangin terhitung 481 peserta KB IUD aktif dan 55 peserta KB IUD pasca persalinan. Pada Puskesmas Tigo Baleh terhitung 594 peserta KB IUD aktif dan 13 peserta KB IUD pasca dari data diatas didapatkan peserta KB IUD aktif dan pasca persalinan terendah pada Puskesmas Mandiangin, Bukittinggi tahun 2018 yaitu sebanyak 48 peserta KB IUD aktif dan jumlah peserta KB pasca persalinan sebanyak 13 orang[5].

Berdasarkan latar belakang diatas, peneliti tertarik melakukan penelitian untuk melihat apakah ada hubungan dukungan suami dengan keikutsertaan ibu akseptor KB IUD di puskesmas Mandiangin, Bukittinggi tahun 2019.

\section{Bahan dan Metode}

Penelitian ini menggunakan desain survey analitik dan pendekatan yang digunakan adalah cross sectional yaitu penelitian dengan cara pendekatan, observasi atau pengumpulan data sekaligus pada saat yang bersamaan.

\section{Populasi dan Sampel}

Populasi dari penelitian ini adalah peserta akseptor KB di Puskesmas Mandiangin Bukittinggi pada bulan Maret 2019 sebanyak 345 peserta.

Sampel pada penelitian ini adalah 69 peserta akseptor KB di Puskesmas Mandiangin Bukittinggi pada bulan April sampai Mei 2019.

\section{Pengumpulan Data}

Dalam hal ini peneliti menggunakan teknik pengumpulan data primer dengan teknik wawancara ke pasien serta pengumpulan data sekunder yaitu data yang di dapat dari dinas kesehatan Bukittinggi dan Puskesmas Mandiangin.

\section{Hasil Penelitian}

\section{Analisa Univariat}

Dari hasil penelitian di dapat pada responden yang berjumlah sebanyak 69 orang responden, mengenai Hubungan Dukungan Suami Dengan Keikutsertaan Ibu Akseptor KB IUD di Puskesmas Mandiangin, Bukittinggi Tahun 2017, sebagai berikut pada tabel di bawah ini :

Tabel 1. Distribusi Frekuensi Dukungan Suami Di Puskesmas Mandiangin Kec. MKS Bukittinggi Tahun 2019

\begin{tabular}{|c|c|c|c|}
\hline No. & Dukungan Suami & Frekuensi & Presentase (\%) \\
\hline 1. & Tidak Mendukung & 23 & 33,3 \\
\hline 2. & Mendukung & 46 & 66,7 \\
\hline Total & & 69 & 100 \\
\hline
\end{tabular}


Berdasarkan tabel 1. diketahui sepertiga responden yang tidak didukung oleh suaminya yaitu sebanyak $33,3 \%$.

Tabel 2. Distribusi Frekuensi Keikutsertaan Ibu Akseptor KB IUD di Puskesmas Mandiangin Kec. MKS Bukittinggi Tahun 2019.

\begin{tabular}{l|lll}
\hline No & Keikutsertaan KB & Frekuensi & Presentase \\
\hline 1. & Tidak Akseptor KB & 33 & 47,8 \\
& IUD & & 52,3 \\
\hline 2. & Akseptor KB IUD & 36 & 100 \\
\hline
\end{tabular}

Berdasarkan tabel 2 diketahui lebih dari sepertiga responden yang tidak menjadi akseptor KB IUD yaitu sebanyak 47,8\%.

Tabel 3. Hubungan Dukungan Suami Dengan Keikutsertaan Ibu Akseptor KB IUD Di Puskesmas Mandiangin Kec. MKS Bukittinggi Tahun 2019

\begin{tabular}{llllll|ll}
\hline Variabel & \multicolumn{9}{l}{ Keikutsertaan KB IUD } & \multicolumn{2}{l}{ P-value } \\
& $\begin{array}{l}\text { Tidak Akseptor KB } \\
\text { IUD }\end{array}$ & Akseptor KB IUD & \multicolumn{2}{l}{ Jumlah } & \\
\hline Dukungan Suami & F & $\%$ & F & $\%$ & F & $\%$ & 0,013 \\
\hline Tidak Mendukung & 10 & 43,5 & 13 & 56,5 & 23 & 100 \\
\hline Mendukung & 23 & 50,0 & 23 & 50,0 & 46 & 100 \\
\hline Total & 33 & 47,8 & 36 & 52,2 & 69 & 100 \\
\hline
\end{tabular}

Dari tabel 3 di atas dapat diketahui bahwa dari 23 orang responden, lebih sepertiga yang tidak memiliki dukungan suami dan tidak menjadi akseptor KB IUD terdapat sebanyak 10 responden $(43,5 \%)$, sedangkan dari 46 orang responden yang memiliki dukungan suami dan tidak menjadi akseptor KB IUD sebanyak 23 responden $(50,0 \%)$.

\section{Pembahasan}

\section{Analisa Univariat}

\section{Dukungan Suami}

Berdasarkan tabel 1 didapatkan sepertiga responden yang tidak didukung oleh suaminya yaitu sebanyak 33,3\% dan lebih dari separoh didukung oleh suaminya yaitu sebanyak 66,7\% di puskesmas Mandiangin, Bukittinggi.

Menurut hasil penelitian Bella Novita (2015), bahwa dukungan suami mempunyai hubungan dalam pengambilan keputusan penggunaan alat kontrasepsi, tetapi suami belum berkontribusi dalam pemilihan metode atau jenis alat kontrasepsi. Hal ini dipengaruhi beberapa faktor misalnya kurang pengetahuan suami akan alat kontrasepsi dan pentingnya pemberian dukungan dalam pemilihan alat kontrasepsi, kesibukan suami dalam merealisasikan perannya sebagai kepala keluarga dalam mencari nafkah untuk memenuhi keperluan keluarga.

Dukungan Suami adalah sumber emosional, informasi atau pendamping untuk menghadapi setiap permasalahan dan krisis yang terjadi sehari-hari dalam kehidupan. Menurut teori Friedman (2010), faktor yang mempengaruhi adanya dukungan suami yaitu 
tahap perkembangan, tingkat pengetahuan, faktor emosi, faktor spiritual, praktik di keluarga, tingkat sosial ekonomi dan faktor latar belakang budaya[6].

Asumsi peneliti bahwa adanya dukungan suami pada istri karena suami memahami keadaan istrinya, serta memahami apa yang diinginkan istrinya. Disisi lain suami juga dapat memberikan dukungan emosional, dukungan penghargaan, dukungan fasilitas, dukungan informatif dalam mendukung istri. Namun ada juga suami yang belum mendukung keinginan istrinya dalam berKB karena dipengaruhi oleh faktor lingkungan, pengetahuan dan agama, dimana faktor pengetahuan suami yang kurang dalam mengetahui manfaat dari kontrasepsi tersebut.

\section{Keikutsertaan $\mathrm{KB}$}

Berdasarkan tabel 2 didapatkan lebih dari sepertiga responden yang tidak menjadi akseptor KB IUD yaitu sebanyak 47,8\% dan separoh responden yang menjadi akseptor KB IUD yaitu sebanyak 52,3\% di puskesmas Mandiangin, Bukittinggi.

Menurut hasil penelitian Agnes Indrilia (2013) menyatakan bahwa ada hubungan yang signifikan antara usia, pendidikan, pekerjaan, dan paritas terhadap keikutsertaan ibu akseptor $\mathrm{KB}$, dimana seseorang dengan tingkat pendidikan lebih tinggi akan memiliki pandangan yang lebih luas tentang suatu hal dan lebih mudah untuk menerima ide atau cara kehidupan baru.

Keikutsertaan KB merupakan suatu bentuk partisipasi dalam mengikuti kegiatan keluarga berencana. Dalam hal ini, keinginan seseorang yang akan menggunakan alat kontrasepsi. Hal yang dilakukan adalah positif dimana terjadi keinginan dengan tujuan sama dalam menjarakan usia anak[4].

Asumsi peneliti bahwa keikutsertaan istri dikarenakan istri mau berpartisipasi dalam berKB dan ingin menjarangkan usia anak. Dalam teori mengatakan bahwa keikutsertaan merupakan suatu bentuk partisipasi dalam mengikuti kegiatan keluarga berencana. Tetapi terdapat fator lain yang membuat ibu tidak ikut berpartisipasi dalam pemakaian KB, seperti mitos, tidak adanya dukungan suami, ketidaktahuan ibu terhadap kontrasepsi IUD, kesibukan dalam pekerjaan .

\section{Analisa Bivariat}

Dari tabel 3 di atas dapat diketahui bahwa dari 23 orang responden, lebih sepertiga yang tidak memiliki dukungan suami dan tidak menjadi akseptor KB IUD terdapat sebanyak 10 responden $(43,5 \%)$, sedangkan dari 46 orang responden yang memiliki dukungan suami dan tidak menjadi akseptor KB IUD sebanyak 23 responden (50,0\%) di Puskesmas Mandiangin Kota Bukittinggi tahun 2019.

Menurut hasil penelitian Dwi Puspitasari (2014) menyebutkan bahwa ada hubungan positif yang signifikan antara dukungan suami dengan keikutsertaan KB pada pasangan usia subur (PUS) di Desa Argomulyo Sedayu Bantul Yogyakarta tahun 2014.

Asumsi peneliti bahwa ada hubungan yang signifikan antara hubungan dukungan suami dengan keikutsertaan ibu yang menjadi akseptor KB IUD. Dukungan suami memiliki peran dalam meningkatkan keutuhan pasangan suami istri dlam melakukan program pemerintah seperti keikutsertaan KB. Dukungan suami mengacu pada suatu dukungan yang dipandang oleh istri sebagai suatu hal yang dapat bermanfaat baik dalam hal pemecahan masalah, pemberian keamanan dan peningkatan harga diri. Pada dasarnya sangat penting dukungan suami yang diberikan kepada istrinya agar istrinya selalu setia melakukan kewajibannya sebagai istri di rumah tangga dan selalu dapat melakukan kehidupan kesehatan dengan melakukan $\mathrm{KB}$ yang dapat meningkatkan kesejahteraan $\operatorname{keluarga}^{(7)}$. 


\section{Kesimpulan}

1. Hampir sebagian besar responden mendapat dukungan dari suami sebanyak 46 orang ibu (66.7\%) mejadi akseptor KB IUD di Puskesmas Mandiangin Kecamatan MKS Kota Bukittinggi tahun 2019

2. Hampir sebagian besar responden menjadi akseptor KB sebanyak 36 orang ibu (62.2\%) mejadi akseptor KB IUD di Puskesmas Mandiangin Kecamatan MKS Kota Bukittinggi tahun 2019

3. Hasil uji statistik didapatkan bahwa ada hubungan Dukungan suami dengan Keikutsertaan KB IUD di Puskesmas Mandiangin Kecamatan MKS Kota Bukittinggi Tahun 2019 dengan pvalue $(0,013<0,05)$

\section{Saran}

1. Bagi pihak puskesmas

Diharapkan penelitian ini menjadi bahan masukan bagi petugas kesehatan di puskesmas agar dapat meningkatkan penyuluhan tentang keikutsertaan dalam ber KB sehingga terciptanya kejahteraan yang baik dalam keluarga.

2. Bagi pihak institusi pendidikan

Diharapkan agar institusi memperbanyak dan mempunyai sumber terbaru sebagai sumber referensi bagi peneliti selanjutnya.

3. Bagi peneliti selanjutnya

Diharapkan bagi peneliti selanjutnya dapat melakukan penelitian lanjutan mengenai faktorfaktor yang berhubungan dengan keikutsertaan KB

\section{Referensi}

[1] World Health Organization (WHO). 2014. Penggunaan Kontrasepsi Di Dunia. Switzerland: World Health Organization.

[2] Kemenkes RI, 2014. Profil Kesehatan Indonesia 2014. Kementrian Kesehatan RI. Jakarta.

[3] Dinas Kesehatan Kota Bukittinggi, 2014

[4] Affandi, Biran. 2013. Buku Panduan Praktis Pelayanan Kontrasepsi; Edisi 3. Jakarta: Bina Pustaka Sarwono Prawirohardjo

[5] Dinas Kesehatan Kota Bukittinggi, 2018

[6] Christabella, Anjani. 2012. Peran Suami dan Kontrasepsi. Artikel Ilmiah, Universitas Sumatra Utara.

[7] Hidayat, A.Aziz Alimul. 2010. Metode Penelitian Kesehatan. Jakarta: Salemba Medika.

[8] Eriska, Putri. 2012. Konsep Dukungan Sosial Suami. Artikel Ilmiah, Universitas Islam Negeri Malang.

[9] Notoatmodjo, Seokidjo. 2010. Metodelogi Penelitian Kesehatan. Jakarta: Rineka Cipta

[10] Notoatmodjo, Seokidjo. 2012. Metodelogi Penelitian Kesehatan. Jakarta: Rineka Cipta

[11]Nugroho, Joko. 2014. BKKBN: Peserta Keluarga Berencana Di Sumatra Barat. http://www.antarasumbar.com, diakses 15 Oktober 2014

[12]Sukardi, 2011. Partisipasi Pria dalam Keluarga Berencana (BKKBN). http://sulbar.bkkbn.go.id, diakses 1 Februari 2011. 